\title{
Effect of hemodialysis on visual acuity, intraocular pressure, and macular thickness in patients with chronic kidney disease
}

This article was published in the following Dove Press journal:

Clinical Ophthalmology

9 January 2015

Number of times this article has been viewed

\author{
Elias Chelala ${ }^{1,2, *}$ \\ Ali Dirani ${ }^{1,2, *}$ \\ Ali Fadlallah ${ }^{1,2}$ \\ Elise Slim ${ }^{1,2}$ \\ Youssef Abdelmassih 1,2 \\ Henry Fakhoury ${ }^{3}$ \\ Patrick Baz ${ }^{1,2}$ \\ Riad Bejjani ${ }^{1,2}$ \\ 'Faculty of Medicine, Saint-Joseph \\ University, ${ }^{2} \mathrm{Hôtel}-\mathrm{Dieu}$ de France \\ Hospital, Saint-Joseph University, \\ ${ }^{3}$ Eye and Ear Hospital, Beirut, Lebanon \\ *These two authors contributed \\ equally to this work
}

Correspondence: Riad Bejjani

Saint-Joseph University, Faculty of Medicine, Campus of Medical Sciences, Rue de Damas, BP I I-5076 Riad el Solh, Beirut II 07 2I80, Lebanon

Tel +96| | 42। 235

Tel +96| | 42| 023

Email rabejjani@gmail.com
Background: The aim of this study was to evaluate the effects of hemodialysis (HD) on visual acuity, intraocular pressure (IOP), and central foveal thickness (CFT) in patients with chronic kidney disease.

Materials and methods: Forty-nine eyes from 49 chronic kidney-disease patients were analyzed. Causes of chronic kidney disease included diabetes mellitus ( $\mathrm{n}=9$ patients), hypertensive nephrosclerosis ( $n=15$ patients), and other causes ( $n=25$ patients). All patients underwent HD in the Dialysis Unit of Hôtel-Dieu de France Hospital. Best-corrected visual acuity, CFT, and IOP were evaluated before and after HD. CFT was measured with spectral domain optical coherence tomography, and IOP was measured with Goldmann applanation tonometry.

Results: Neither decimal best-corrected visual acuity (pre-HD $0.71 \pm 0.32$, post-HD $0.72 \pm 0.31$; $P=0.877$ ) nor CFT (pre-HD 251.39 \pm 39.29 , post-HD 253.09 $\pm 39.26 ; P=0.272$ ) significantly changed after HD. However, mean IOP significantly decreased from $13.99 \pm 2.48$ before HD to $12.65 \pm 2.41 \mathrm{mmHg}$ after HD $(P=0.001)$. IOP change was significantly correlated with serum albumin levels $(P=0.008)$ and weight changes $(P=0.047)$.

Conclusion: HD can affect various ocular parameters. This is particularly true of IOP, which decreases significantly following HD.

Keywords: chronic kidney disease, hemodialysis, visual acuity, central macular thickness, intraocular pressure

\section{Background}

Patients with chronic kidney disease (CKD) are generally treated using a bloodfiltration mechanism, such as hemodialysis (HD). During HD, numerous metabolic parameters can change, including blood urea, sodium, potassium, and glucose levels. These fluctuations result in osmotic changes in blood, aqueous and vitreous humor, and other extracellular fluids. Visual acuity, intraocular pressure (IOP), and retinal thickness can also be affected.

The effects of HD on the eyes of CKD patients can vary widely. These include changes in visual acuity, IOP, retinal thickness, and refraction. ${ }^{1}$ Changes in the ocular surface have also been observed. In addition, pathologies of the cornea, conjunctiva, lens, and/or retina can develop during an HD-treatment period. Disturbances in the retrobulbar circulation have also been documented following HD. ${ }^{2-6}$ In contrast, some studies have reported no changes in ocular parameters following HD, a difference that could have resulted from examining different CKD subgroups. Unfortunately, few reports have compared ocular parameter changes with HD between different CKD subtypes.

This study examined the short-term changes in ophthalmologic findings, including best-corrected visual acuity (BCVA), IOP, and central foveal thickness (CFT) before 
and after a single HD session. The relationships between these changes and systemic hemodynamic parameters (eg, body weight and systolic and diastolic arterial blood pressure after HD) were evaluated. Finally, the effects of HD on the eye were evaluated and compared between cases of kidney diseases caused by diabetes mellitus (DM), hypertension, and other causes.

\section{Materials and methods Subjects}

This prospective study was conducted in 2012, and included 49 CKD patients ( 27 male and 22 female patients) who were undergoing HD in the Dialysis Unit of Hôtel-Dieu de France Hospital (Beirut, Lebanon). Informed consent was obtained from all subjects, and study conduct adhered to the Declaration of Helsinki. Institutional review board approval was also obtained from the Hôtel-Dieu de France Hospital. Subjects included in the study generally underwent two or three 3- to 4-hour-long HD sessions each week. The characteristics of the HD session were as follows: conventional HD, consisting of a schedule of two or three HD sessions per week using a Hospal Integra monitor, using a dialyzer with a $2 \mathrm{~m}^{2}$ polyarylethersulfone membrane (kUF $27.1 \mathrm{~mL} / \mathrm{h} / \mathrm{mmHg}$, Qd $500 \mathrm{~mL} / \mathrm{min}$ with a composition of sodium 140, calcium $3 \mathrm{mg} \mathrm{0.75}$, and K $1.5 \mathrm{mEq} / \mathrm{L}$ ).

Patients were included in the study if they had a BCVA better than 20/200 and were willing and able to undergo a complete ophthalmologic examination. Exclusion criteria included the presence of an ocular disease that would interfere with retinal examination and/or IOP measurement and prior ocular surgery, laser therapy, or intraocular injection within 3 months of enrollment.

\section{Study examinations}

A detailed ophthalmologic examination was performed on each subject, which included measurements of BCVA, IOP, and macular thickness. Each measurement was made on every subject within an hour before beginning and within an hour after completing a single HD session. BCVA was assessed using a Snellen scale, and is reported as decimal BCVA. IOP was measured using a slit-lamp mounted Goldmann applanation tonometer, and central macular thickness (CMT) was measured using spectral domain optical coherence tomography (SD-OCT) macular mapping (Optovue, Fremont, CA, USA) to obtain a macular thickness map. The central foveal subfield-thickness measurement was used in analyses. Additionally, pre- and post-HD venous blood samples were collected through standard venipuncture techniques to measure serum albumin, sodium, and urea levels. Body weight and blood pressure were also measured before and after HD.

\section{Statistical analyses}

Ophthalmologic data were collected from the right eyes of all subjects. A Wilcoxon signed-rank test was used to compare BCVA, IOP, and CMT before and after HD sessions. A Pearson correlation test was used to examine possible relationships between changes in ophthalmologic parameters and other measured parameters. Statistical software (SPSS version 17.0; SPSS, Chicago, IL, USA) was used to perform all statistical analyses, with statistical significance defined as a $P$-value $<0.05$.

\section{Results \\ Demographic characteristics}

A total of 49 patients (27 male and 22 female patients) were enrolled in this study. Average patient age was $68.0 \pm 12.7$ years, and subjects had been undergoing dialysis for a mean period of $5.2 \pm 4$. 1 years. Causes of CKD are summarized in Table 1, and included DM (group 1, nine patients), hypertensive nephrosclerosis (group 2, 15 patients), and other causes (group 3, 25 patients).

\section{Effects of HD}

A statistically significant change from pre-HD values in body weight, systolic blood pressure, diastolic blood pressure, and sodium level were observed following an HD session $(P<0.001)$, as summarized in Table 2. Mean changes in body weight, systolic blood pressure, diastolic blood pressure, and serum sodium concentration were

Table I Causes of chronic renal failure

\begin{tabular}{ll}
\hline Disease & $\mathbf{n}$ \\
\hline Diabetes & 9 \\
Hypertension & 15 \\
Berger's disease & 2 \\
MPG & 1 \\
CGN & 3 \\
FSG & 2 \\
Renal carcinoma in nephrectomized patient & 3 \\
CIN & 2 \\
Oxalosis & 1 \\
PKD & 7 \\
Postrenal causes & 1 \\
Unknown & 1 \\
VHL disease & 2 \\
\hline Abbreviatis: MPG, mbraprolfar
\end{tabular}

Abbreviations: MPG, membranoproliferative glomerulonephritis; CGN, chronic glomerulonephritis; FSG, focal segmental glomerulonephritis; CIN, chronic interstitial nephritis; PKD, polycystic kidney disease; VHL, Von Hippel-Lindeau. 
Table 2 Effect of hemodialysis on systemic parameters

\begin{tabular}{llll}
\hline & Pre-HD & Post-HD & P-value \\
\hline Body weight $(\mathrm{kg})$ & $74.53 \pm 16.38$ & $72.15 \pm 16.25$ & 0.001 \\
Systolic BP $(\mathrm{mmHg})$ & $141.29 \pm 16.78$ & $119.61 \pm 21.20$ & $0.00 \mathrm{I}$ \\
Diastolic BP $(\mathrm{mmHg})$ & $74.98 \pm 12.02$ & $66.84 \pm 12.56$ & $0.00 \mathrm{I}$ \\
Serum sodium level $(\mathrm{mmol} / \mathrm{L})$ & $138.65 \pm 2.86$ & $141.68 \pm 2.15$ & 0.001 \\
Urea-reduction ratio & $0.73 \pm 0.06$ & $0.73 \pm 0.06$ & - \\
\hline
\end{tabular}

Abbreviations: HD, hemodialysis; BP, blood pressure.

$2.4 \pm 0.9 \mathrm{~kg}, 21.7 \pm 22.5 \mathrm{mmHg}, 8.1 \pm 17.3 \mathrm{mmHg}$, and $3.0 \pm 3.2 \mathrm{mmol} / \mathrm{L}$, respectively. The urea-reduction ratio (URR) was $0.73 \pm 0.06$.

BCVA (pre-HD 0.71 0.32 , post-HD 0.72 \pm 0.31 ; $P=0.877$ ) and CMT (pre-HD 251.39 $\pm 39.29 \mu \mathrm{m}$, post-HD $253.09 \pm 39.26 ; P=0.272$ ) did not significantly change in a single HD session, but mean IOP was significantly reduced from $13.99 \pm 2.48 \mathrm{mmHg}$ before $\mathrm{HD}$ to $12.65 \pm 2.41 \mathrm{mmHg}$ after HD $(P=0.001)$. Additionally, HD did not affect the eyes of patients with different CKD subtypes differently, as summarized in Tables 3 and 4. Within each group, BCVA and CMT were not affected by one HD session, but IOP was significantly decreased (Tables 3 and 4).

An analysis was performed to determine if HD-induced changes in IOP were correlated with baseline serum albumin levels, sodium levels, systolic blood pressure, diastolic blood pressure, and weight. HD-induced changes in these parameters were also examined, along with URRs and ultrafiltration rates (Table 5). Changes in IOP were significantly correlated with baseline albumin levels $(P=0.008)$ and weight changes $(P=0.047)$.

Table 3 Effect of hemodialysis on ocular parameters

\begin{tabular}{llll}
\hline & Pre-HD & Post-HD & P-value \\
\hline All patients & & & \\
Decimal BCVA & $0.71 \pm 0.32$ & $0.72 \pm 0.3 \mathrm{I}$ & 0.877 \\
IOP & $13.99 \pm 2.48$ & $12.65 \pm 2.4 \mathrm{I}$ & $0.00 \mathrm{I}$ \\
CMT & $251.39 \pm 39.29$ & $253.09 \pm 39.26$ & 0.272 \\
Diabetes mellitus & & & \\
BCVA & $0.49 \pm 0.37$ & $0.52 \pm 0.36$ & 0.084 \\
IOP & $14.37 \pm 2.36$ & $12.06 \pm 1.65$ & 0.001 \\
CMT & $286.0 \pm 61.77$ & $283.50 \pm 57.12$ & 0.414 \\
Hypertension & & & \\
Decimal BCVA & $0.60 \pm 0.26$ & $0.59 \pm 0.29$ & 0.574 \\
IOP & $14.73 \pm 2.38$ & $13.08 \pm 2.15$ & 0.006 \\
CMT & $257.48 \pm 43.24$ & $252.80 \pm 29.62$ & 0.965 \\
Other causes & & & \\
Decimal BCVA & $0.86 \pm 0.23$ & $0.88 \pm 0.21$ & $0.27 \mathrm{I}$ \\
IOP & $13.97 \pm 2.67$ & $12.6 \pm 2.79$ & 0.020 \\
CMT & $239.47 \pm 24.17$ & $240.42 \pm 26.31$ & 0.328 \\
\hline
\end{tabular}

Abbreviations: HD, hemodialysis; BCVA, best-corrected visual acuity; IOP, intraocular pressure; CMT, central macular thickness.

\section{Diabetic chronic kidney disease subjects}

Two patients with CKD from DM were diagnosed with diabetic retinopathy: one patient with nonproliferative diabetic retinopathy, and one patient with proliferative diabetic retinopathy. The patient with proliferative diabetic retinopathy had undergone a previous panretinal photocoagulation laser treatment. Additionally, four patients had diabetic macular edema at the time of enrollment. These patients had previously undergone focal and grid laser therapy or intravitreal injection for diabetic macular edema. All laser and injection therapies had been performed more than 3 months before study enrollment. In this subgroup of patients, BCVA was not changed by a single HD session (pre-HD $0.36 \pm 0.26$, post-HD $0.29 \pm 0.32 ; P=0.837$ ). CMT was slightly decreased (pre-HD $393.5 \pm 42.5 \mu \mathrm{m}$, post-HD $385.3 \pm 49.0 \mu \mathrm{m}$ ), but this small change was not statistically significant $(P=0.317)$.

\section{Discussion}

During HD, numerous metabolic parameters change, including blood urea, sodium, potassium, and glucose levels, which also induce osmotic changes in blood and extracellular fluids. This includes the aqueous and vitreous humor, changes in which can result in visual acuity, IOP, and retinal thickness changes. In our study, BCVA did not significantly change following a single HD session, but IOP significantly decreased from $13.99 \pm 2.48 \mathrm{mmHg}$ before HD to $12.65 \pm 2.41 \mathrm{mmHg}$ after HD. This IOP change was significantly correlated with pre-HD serum albumin levels and weight change. CMT, as measured on SD-OCT, was not significantly affected by HD.

Many conflicting results have been published on the effects of HD on IOP. This remains controversial, but many theories have been proposed to explain these varying results. Rever et $\mathrm{al}^{7}$ concluded that IOP did not significantly change during $\mathrm{HD}$, whether acetate or bicarbonate was used in the dialysate.

Our study demonstrated a slight but significant decrease in IOP with HD that was independent of end-stage renal disease cause. Our findings also revealed that changes in IOP were significantly correlated with pre-HD albumin levels 
Table 4 Change in ophthalmologic parameters with hemodialysis in each chronic kidney-disease subtype

\begin{tabular}{lllll}
\hline & DM group & HTN group & Other cause & $P$-value \\
\hline Mean BCVA change & $-0.04 \pm 0.02$ & $0.02 \pm 0.03$ & $0.03 \pm 0.01$ & 0.219 \\
Mean IOP change & $2.31 \pm 0.44$ & $1.65 \pm 0.4 \mathrm{I}$ & $1.37 \pm 0.38$ & $0.06 \mathrm{I}$ \\
Mean CMT change & $-2.50 \pm 1.39$ & $-4.68 \pm 2.00$ & $-0.95 \pm 2.65$ & 0.896 \\
\hline
\end{tabular}

Abbreviations: DM, diabetes mellitus; HTN, hypertension; BCVA, best-corrected visual acuity; IOP, intraocular pressure; CMT, central macular thickness.

and weight change during HD. However, IOP changes were not correlated with HD-induced changes in serum sodium, blood pressure, URR, ultrafiltration rate, or blood pressure changes.

Other studies have shown similar results, with reductions in IOP varying between 0.8 and $1.3 \mathrm{mmHg}$. Unfortunately, few of these reports proposed a mechanism by which this IOP reduction occurred. ${ }^{7-9}$ Tokuyama et al ${ }^{10}$ related IOP reduction to ultrafiltration rate by the mean of albumin level. Ultrafiltration leads to a gradual reduction of extracellular fluid. Oncotic pressure increases due to ultrafiltration because large proteins, such as albumin and globulin, cannot cross the membranes, so there will be a colloid gradient between plasma and interstitial fluid and water moves from the interstitial and aqueous humor to plasma fluid. These changes in oncotic pressure and ultrafiltration lead to a decline in IOP at the end of dialysis. IOP change is greater with a higher plasma albumin level and degree of ultrafiltration (greater weight change). ${ }^{10}$

Underestimating IOP values after HD sessions can happen because of decreases in central corneal thickness induced by fluid loss. ${ }^{7}$ Jung et al $^{11}$ showed a significant decrease in central corneal thickness during HD (mean change of approximately $7 \mu \mathrm{m}$ ), and that CMT and IOP changes were positively correlated. Broekema et a $\mathrm{l}^{12}$ suggested that despite a decrease in blood osmolality, other regulatory forces prevent significant fluctuations in IOP during HD. In that study, the IOP decrease was more pronounced in nondiabetic patients than in diabetic patients, possibly due to fluctuations in blood glucose levels. Other studies have shown significant correlations between serum osmolarity and IOP fluctuations during HD. These reports proposed that a difference in ocular fluid and plasma osmolarity can result in IOP fluctuations. ${ }^{12,13}$ This IOP increase was also more pronounced in patients with obstructed aqueous outflow pathways. ${ }^{14}$

Tovbin et $\mathrm{al}^{15}$ implied that postdialysis urea rebound (PDUR) changes are related to IOP changes during HD. During the HD procedure, urea removal from the cellular compartment lags behind its removal from the extracellular compartment, creating a gap between cellular and serum urea levels. This gap is reversed as urea moves from cells to the extracellular fluid after dialysis, as reflected in PDUR. This gap may induce water movement from extracellular fluid to intracellular spaces during dialysis. In the report, it was suggested that PDUR is strongly correlated with intradialytic changes in IOP, and that these changes can predict IOP elevations in the presence of lower hemoconcentrations during dialysis. ${ }^{15,16}$ In our study, we did not observe a significant relationship between IOP changes and URR.

In eyes with glaucoma, narrow angles, or impaired aqueous outflow, acute rises in IOP during HD could occur much more frequently than in normal patients. Lower plasma osmolarity, compared to aqueous humor osmolarity, and a relative increase in aqueous humor-urea concentration may

Table 5 Correlations between intraocular pressure and systemic parameters

\begin{tabular}{llll}
\hline & Mean \pm SD & Correlation, $\boldsymbol{r}$ & Correlation, $\boldsymbol{P}$ \\
\hline Serum albumin before HD $(\mathrm{g} / \mathrm{L})$ & $36.93 \pm 3.95$ & 0.303 & 0.008 \\
Serum sodium before HD $(\mathrm{mmol} / \mathrm{L})$ & $138.65 \pm 2.86$ & -0.085 & 0.455 \\
Systolic BP before HD $(\mathrm{mmHg})$ & $141.29 \pm 16.78$ & -0.125 & 0.264 \\
Diastolic BP before HD $(\mathrm{mmHg})$ & $74.98 \pm 12.02$ & -0.174 & 0.118 \\
Weight before HD $(\mathrm{kg})$ & $74.53 \pm 16.38$ & 0.039 & 0.726 \\
Change in serum sodium $(\mathrm{mmol} / \mathrm{L})$ & $-3.04 \pm 3.19$ & -0.083 & 0.463 \\
Change in systolic BP $(\mathrm{mmHg})$ & $21.67 \pm 22.50$ & 0.178 & 0.110 \\
Change in diastolic BP $(\mathrm{mmHg})$ & $8.14 \pm 17.34$ & -0.089 & 0.446 \\
Change in weight $(\mathrm{kg})$ & $2.38 \pm 0.93$ & 0.220 & 0.047 \\
Urea-reduction ratio & $0.73 \pm 0.06$ & -0.001 & 0.992 \\
Ultrafiltration rate & $3.67 \pm 0.88$ & 0.186 & 0.094 \\
\hline
\end{tabular}

Abbreviations: SD, standard deviation; $\mathrm{HD}$, hemodialysis; $\mathrm{BP}$, blood pressure. 
contribute to increases in IOP ${ }^{16}$ Observed differences in IOP fluctuations may also have resulted from differences in dialysis technique and duration. ${ }^{16}$

HD patients often complain of both acute and chronic vision changes. Acute changes could be secondary to changes in parameters during HD, but chronic changes most often result from eye disease secondary to the primary cause of renal insufficiency (eg, diabetes mellitus, hypertension). In the current study, BCVA was not significantly different before and after a single HD session, but the largest changes were observed in patients with diabetes-related renal failure. Interestingly, diabetic patients tended to show improvements in BCVA with HD, but these changes were not significant. Furthermore, diabetic patients tended to begin dialysis with a lower BCVA than nondiabetic patients. In agreement with our results, other studies have demonstrated a positive correlation between BCVA and blood glucose, as well as an association with a history of diabetic retinopathy. ${ }^{17}$

Tomazzoli et al ${ }^{18}$ showed that a change in refraction was noted in $64 \%$ of eyes in HD patients, and that this change was always toward hyperopia. We did not examine refractive properties of the eye in our study. It has also been shown that older diabetic patients have more severe visual impairment than their younger counterparts, and that this impairment is generally less amenable to correction. ${ }^{19}$

Overall, visual acuity depends on the health of the cornea, lens, and retina, as well as the axial length, all of which are prone to change during HD and with blood glucose fluctuations. ${ }^{11,20}$ Our study demonstrated a significant decrease in IOP during an HD session, which can affect visual acuity from resulting changes in corneal thickness and corneal refractive power. Additionally, it has been shown that blood glucose fluctuations, which affect plasma osmolarity, can alter IOP, zonular tension, anterior-chamber depth, and lens thickness, all of which can affect visual acuity. ${ }^{21}$

Giusti $^{22}$ demonstrated that hyperglycemia affects visual acuity by causing a hyperopic shift. Hyperopic changes were positively correlated with blood glucose levels and were reversed with correction of hyperglycemia. The most accepted explanation for these refractive changes stems from lens-osmolarity and sorbitol-production changes, which result from excess hydration of the lens. This directly results in alterations of lens shape and refractive power. ${ }^{22}$

Other studies have related changes in vision with HD to changes in the retina, particularly macular thickness. This would help explain vision changes in patients who do not have fluctuations in blood glucose levels during HD. ${ }^{23,24}$ Another line of thinking suggests that HD-induced visual acuity changes result from ocular surface changes. Both tear-breakup time and basal tear secretion (as measured by Schirmer's test) have been shown to decrease during HD, with a concomitant increase in keratoepitheliopathy score. ${ }^{11}$

Finally, several studies have shown that HD affects retinal thickness. Macular thickness improvements have been observed with HD. ${ }^{25,26}$ These studies had different follow-up periods. Additionally, they examined retinal thickness using fluorescein angiography and ophthalmoscopy. In contrast, we found no significant effect of HD on CMT, as measured with SD-OCT. This is in agreement with the results of more recent studies, which used OCT to measure both retinal and foveal thickness. Pahor et $\mathrm{al}^{27}$ demonstrated a significant decrease in retinal thickness, but not subfoveal thickness, in all retinal quadrants following HD. Ulaş et $\mathrm{al}^{28}$ found no change in foveal, temporal, or nasal retinal thickness, but did observe a significant reduction in choroidal thickness in all four quadrants of 21 patients. Yang et $\mathrm{al}^{20}$ found similar results, along with a correlation between choroidal thinning and body-weight reductions. Auyanet et $\mathrm{al}^{24}$ found that some HD parameters could affect macular thickness, especially bath temperature and conductivity. Lastly, Jung et al ${ }^{11}$ recently demonstrated a significant decrease in central subfoveal thickness of approximately $7 \mu \mathrm{m}$, but this decrease was not correlated with any systemic parameter. We also found no significant decrease in CMT with dialysis. It may be that thickness is affected by how far into HD measurements are made. The first studies to show that HD improved macular edema were done using fluorescein angiography in patients who had recently begun HD, but more recent OCT studies were done on chronic HD patients. The cause of renal failure and the extent of diabetic retinopathy could also affect how CMT changes with dialysis.

In conclusion, all causes of CKD can directly affect the eyes, but ocular changes can also result from HD itself. Decreases in IOP and changes in vision have been shown to occur after $\mathrm{HD}$, especially in diabetic patients. However, changes in vision were not statistically significant in our study. Additionally, HD did not change CMT, as measured with OCT.

\section{Disclosure}

The authors report no conflicts of interest in this work.

\section{References}

1. Vrabec R, Vatavuk Z, Pavlović D, et al. Ocular findings in patients with chronic renal failure undergoing haemodialysis. Coll Antropol. 2005; 29 Suppl 1:95-98.

2. Diaz-Couchoud P, Bordas FD, Garcia JR, Camps EM, Carceller A. Corneal disease in patients with chronic renal insufficiency undergoing hemodialysis. Cornea. 2001;20(7):695-702. 
3. Charlton JF, Schwab IR, Stuchell R. Tear hyperosmolarity in renal dialysis patients asymptomatic for dry eye. Cornea. 1996;15(4):335-339.

4. Niutta A, Spicci D, Barcaroli I. Fluoroangiographic findings in hemodialyzed patients. Ann Ophthalmol. 1993;25(10):375-380.

5. Tosun O, Davutluoglu B, Arda K, et al. Determination of the effect of a single hemodialysis session on retrobulbar blood hemodynamics by color Doppler ultrasonography. Acta Radiol. 2007;48(7):763-767.

6. Mullaem G, Rosner MH. Ocular problems in the patient with end-stage renal disease. Semin Dial. 2012;25(4):403-407.

7. Rever B, Fox L, Bar-Khayim Y, Nissenson A. Adverse ocular effects of acetate hemodialysis. Kidney Int. 1981;19(1):157.

8. Dinc UA, Ozdek S, Aktas Z, Guz G, Onol M. Changes in intraocular pressure, and corneal and retinal nerve fiber layer thickness during hemodialysis. Int Ophthalmol. 2010;30(4):337-340.

9. Afshar R, Ghasemi H, Shabpiray H, et al. Monitoring of intraocular pressure and its correlation with systemic parameters before and after hemodialysis. Iran J Kidney Dis. 2013;7(1):53-59.

10. Tokuyama T, Ikeda T, Ishikawa H, Sato K. Marked decrease in intraocular pressure in a neovascular glaucoma patient during hemodialysis. Jpn J Ophthalmol. 1997;41(2):101-103.

11. Jung JW, Yoon MH, Lee SW, Chin HS. Effect of hemodialysis (HD) on intraocular pressure, ocular surface, and macular change in patients with chronic renal failure. Effect of hemodialysis on the ophthalmologic findings. Graefes Arch Clin Exp Ophthalmol. 2013;251(1):153-162.

12. Broekema N, van Bijsterveld OP, de Bos Kuil RJ. Intraocular pressure during hemodialysis. Ophthalmologica. 1988;197(2):60-64.

13. Leiba H, Oliver M, Shimshoni M, Bar-Khayim Y. Intraocular pressure fluctuations during regular hemodialysis and ultrafiltration. Acta Ophthalmol (Copenh). 1990;68(3):320-322.

14. Dujić M, Marković P, Jovanović D, Dragićević P, Radovanović L. [Changes in intraocular pressure during dialysis]. Srp Arh Celok Lek. 1997;125(9-10):257-260. Serbian.

15. Tovbin D, Belfair N, Shapira S, et al. High postdialysis urea rebound can predict intradialytic increase in intraocular pressure in dialysis patients with lowered intradialytic hemoconcentration. Nephron. 2002;90(2):181-187.

16. Levy J, Tovbin D, Lifshitz T, Zlotnik M, Tessler Z. Intraocular pressure during haemodialysis: a review. Eye (Lond). 2005;19(12):1249-1256.
17. Ghasemi H, Afshar R, Zerafatjou N, et al. Impact of hemodialysis on visual parameters in patients with end-stage renal disease. Iran J Kidney Dis. 2012;6(6):457-463.

18. Tomazzoli L, De Natale R, Lupo A, Parolini B. Visual acuity disturbances in chronic renal failure. Ophthalmologica. 2000;214(6):403-405.

19. Bloomgarden ZT. Screening for and managing diabetic retinopathy: current approaches. Am J Health Syst Pharm. 2007;64(17 Suppl 12): S8-S14.

20. Yang SJ, Han YH, Song GI, Lee CH, Sohn SW. Changes of choroidal thickness, intraocular pressure and other optical coherence tomographic parameters after haemodialysis. Clin Exp Optom. 2013;96(5):494-499.

21. Furushima M, Imaizumi M, Nakatsuka K. Changes in refraction caused by induction of acute hyperglycemia in healthy volunteers. Jpn J Ophthalmol. 1999;43(5):398-403.

22. Giusti C. Transient hyperopic refractive changes in newly diagnosed juvenile diabetes. Swiss Med Wkly. 2003;133(13-14):200-205.

23. Theodossiadis PG, Theodoropoulou S, Neamonitou G, et al. Hemodialysis-induced alterations in macular thickness measured by optical coherence tomography in diabetic patients with end-stage renal disease. Ophthalmologica. 2012;227(2):90-94.

24. Auyanet I, Rodríguez LJ, Bosch E, et al. Measurement of foveal thickness by optical coherence tomography in adult haemodialysis patients with diabetic nephropathy. Nefrologia. 2011;31(1):66-69.

25. Bresnick GH, Mukamel DB, Dickinson JC, Cole DR. A screening approach to the surveillance of patients with diabetes for the presence of vision-threatening retinopathy. Ophthalmology. 2000;107(1):19-24.

26. Perkovich BT, Meyers SM. Systemic factors affecting diabetic macular edema. Am J Ophthalmol. 1988;105(2):211-212.

27. Pahor D, Gracner B, Gracner T, Hojs R. [Optical coherence tomography findings in hemodialysis patients]. Klin Monbl Augenheilkd. 2008;225(8):713-717. German.

28. Ulaş F, Doğan Ü, Keleş A, Ertilav M, Tekçe H, Celebi S. Evaluation of choroidal and retinal thickness measurements using optical coherence tomography in non-diabetic haemodialysis patients. Int Ophthalmol. 2013;33(5):533-539.

\section{Clinical Ophthalmology}

\section{Publish your work in this journal}

Clinical Ophthalmology is an international, peer-reviewed journal covering all subspecialties within ophthalmology. Key topics include: Optometry; Visual science; Pharmacology and drug therapy in eye diseases; Basic Sciences; Primary and Secondary eye care; Patient Safety and Quality of Care Improvements. This journal is indexed on Submit your manuscript here: http://www.dovepress.com/clinical-ophthalmology-journal

\section{Dovepress}

PubMed Central and CAS, and is the official journal of The Society of Clinical Ophthalmology (SCO). The manuscript management system is completely online and includes a very quick and fair peer-review system, which is all easy to use. Visit http://www.dovepress.com/ testimonials.php to read real quotes from published authors. 